\title{
Why radioiodine remnant ablation is right for most patients with differentiated thyroid carcinoma
}

\author{
Frederik A. Verburg • Markus Dietlein • \\ Michael Lassmann • Markus Luster • Christoph Reiners
}

Published online: 3 December 2008

(C) Springer-Verlag 2008

Keywords Endocrinology Oncology $\cdot$ Radionuclide therapy $\cdot$ Ablation $\cdot$ Thyroid carcinoma $\cdot$ Radioiodine

Recently an editorial by Hay et al. was published in the Journal of Nuclear Medicine favouring abolishing the use of postoperative radioiodine ablation of thyroid remnant tissue (RRA) in what they called 'stage I' patients [1]. In our opinion the arguments of our distinguished colleagues throw out the baby with the bathwater. In this article we outline a compelling case for the current practice of applying RRA in most patients when regarding the available evidence from another angle.

For many years the recommended therapy for differentiated thyroid carcinoma (DTC), with the exception of microcarcinoma, has consisted of (near-)total thyroidectomy followed by postoperative RRA. Even though results from randomized controlled trials are still missing, this combination has proven its worth as a safe and very effective treatment that results in an improved life expectancy and reduced recurrence rate for patients with DTC in many observational studies. For

\footnotetext{
F. A. Verburg $\cdot$ M. Lassmann $\cdot$ C. Reiners $(\varangle)$

Department of Nuclear Medicine, University Clinic Würzburg, Josef Schneiderstraße 2, Bau D5,

97080 Würzburg, Germany

e-mail: reiners@nuklearmedizin.uni-wuerzburg.de

M. Dietlein

Department of Nuclear Medicine,

University Hospital Cologne,

Cologne, Germany

M. Luster

Department of Nuclear Medicine, University Hospital Ulm,

Ulm, Germany
}

example, in a survey from North America [2] the majority of physicians are convinced that RRA decreases DTC-related mortality and recurrence, and facilitates DTC follow-up with a low risk of adverse effects. RRA has been adopted as an integral part of several recent international guidelines for the treatment of DTC, such as those of the American Thyroid Association [3], the European Thyroid Association [4], and the European Association of Nuclear Medicine [5], as well as several national guidelines in countries such as the UK, Germany [6, 7], the Netherlands and Austria.

In clinical practice, RRA treatment has three goals, as summarized by Schlumberger [8]. First, ${ }^{131}$ I therapy may destroy occult microscopic cancer foci, thereby decreasing the long-term risk of recurrent disease [9-12]. Second, it destroys any remaining normal thyroid tissue, thereby increasing the specificity of detectable serum thyroglobulin (Tg) and positive whole-body scintigraphy as markers for persistent or recurrent tumour $[8,10,13]$. Third, the use of a large activity of ${ }^{131} \mathrm{I}$ for therapy permits postablative scanning, a test for detecting persistent or metastatic carcinoma $[14,15]$; upon finding a focus of such persistent or metastatic carcinoma it will also allow precise probeguided removal of such foci in selected cases [16]. Achieving these goals should, through therapy of micrometastases and more sensitive follow-up, lead to a decreased recurrence rate and, more importantly, an improved tumour-specific survival [9].

Over the years several studies have documented the beneficial effects of RRA. Mazzaferri and Jhiang [9] have shown that ${ }^{131} \mathrm{I}$ is of benefit in all patients except those with stage I disease (defined as unifocal nonmetastasized carcinomas $<1.5 \mathrm{~cm}$ ). RRA leads to a clearly decreased recurrence and mortality rate. In this study no further data were given on the effects of RRA in patients with such 
small carcinomas, presumably for lack of events. Another study by the National Cooperative Thyroid Cancer Treatment Study Group demonstrated a beneficial effect of radioiodine therapy in all patients except those with stage I disease [17]. Unfortunately, group I in this study consisted of a large sample of young patients with the disease extent varying from microcarcinomas to microscopic extraglandular invasion or cervical lymph node metastases. For this category I, a further analysis of the presence or absence of a beneficial effect of RRA treatment according to tumour size, extrathyroidal invasion and the presence of cervical lymph node metastases was not reported.

Nonetheless, in a recent study the probability of lymphogenic micrometastases significantly increased in papillary thyroid cancer (PTC) above a tumour diameter cut-off of $5 \mathrm{~mm}$ [18]. Machens et al. found a linear relationship between tumour size and the risk of lymphogenic metastases. Therefore the small PTC is not always synonymous with a 'low-risk' constellation, especially considering that lymph node spread is a risk factor for distant metastases in PTC.

A recently updated meta-analysis by Sawka et al. [19] concluded that RRA may be effective with regard to tumour-specific survival in low risk patients, but cannot yet be definitively verified on the basis of the available literature. In part the heterogeneity of the various studies (such as the examples given above) on the subject, and also the inherently very favourable prognosis in DTC patients with low stages of disease are to blame here. A remarkable new finding in this update is that patients after RRA showed a significantly lower number of new distant metastases in the course of the disease. As a surrogate measure for a better prognosis this finding could be considered evidence for the effectiveness of RRA treatment [19].

In recent years, new evidence has emerged that lends additional support to performing RRA treatment. Shattuck et al. [20] found that in at least $50 \%$ of patients with multifocal disease the different tumour foci were of independent clonal origin. This indicates that patients with DTC most likely have a heightened susceptibility to the development of multiple primary thyroid carcinomas; RRA treatment would presumably prevent the development of such second primaries in any remaining thyroid tissue.

The nonrandomized studies mentioned above are just examples demonstrating the use of RRA treatment. They also highlight the problem in comparing such studies in terms of outcome: in the various studies different 'staging' systems were used, in which the lowest risk stages varied widely. Therefore recent internationally acclaimed guidelines and consensus statements [3, 4, 21, 22] at least clearly categorize patients who should not, who might, and who should receive RRA treatment according to the (pathological) extension of the disease. In a further development of staging, even RRA treatment itself may facilitate staging and further follow-up of DTC. Verburg et al. [23] have shown that there is a difference in prognosis between patients in whom RRA treatment is successful and those in whom it is not. Preliminary analyses of our patient population indicate that the benefits of RRA may even extend further. After successful RRA treatment, among patients with high-risk disease characteristics according to the definition of the 2006 European consensus [4] there appears to be no difference in disease-free and cancer-specific survival between those at 'high risk' and those who are not.

In their recent editorial, Hay et al. [1] sharply questioned the ubiquitous and liberal use of RRA, especially in stage I patients. Unfortunately, they did not specify according to which staging system they defined stage I. Presumably stage I according to the UICC-AJCC TNM staging system is meant here; however, some authors involved have a long record of propagating alternative staging systems [24, 25]. The authors point out that in populations under their own care [26], they have not been able to demonstrate a beneficial effect of RRA in these 'stage-I' patients.

In some parts of the world, including North America, the patient population referred for thyroid surgery is quite different from that in areas of iodine deficiency such as Germany [27]. In such iodine-deficient areas up to $50 \%$ of thyroid cancers are encountered unexpectedly after (sub) total (hemi)thyroidectomy for benign goitre. Consequently relatively large thyroid remnants often remain as a surgical aim is to spare the recurrent laryngeal nerves and the parathyroid glands. This is in sharp contrast to the situation in highly specialized clinics in iodine-sufficient parts of the world such as the USA, where the a-priori suspicion of malignancy of a given nodule is much higher, which in turn results in the removal of as much thyroid tissue as possible. Whereas in the latter situation the surgery might often make RRA treatment superfluous (especially in less-extensive disease), in the former situation there is always the dilemma of weighing the large risk of disabling recurrent laryngeal nerve damage when reoperating against the relatively low risks of RRA. When faced with this choice, both physician and patient will nearly always opt for RRA.

Hay et al. also question whether achieving an undetectable $\mathrm{Tg}$ level is better than monitoring the trend in $\mathrm{Tg}$ levels. Such a policy has not yet been shown to be equal to monitoring whether $\mathrm{Tg}$ levels remain undetectable. At least a previously undetectable $\mathrm{Tg}$ level returning to a detectable level will prompt earlier action than an increase which may lie well within the day-to-day variation of Tg levels when thyroid tissue is remaining.

Even the proponents of RRA should not lose sight of the risks associated with this treatment. There are side effects such as transient stomatitis and sialadenitis [28, 29], and occasional reports of lacrimal duct damage [30]. Also in 
recent years a lot of discussion has taken place as to whether, and to what extent, RRA causes secondary malignancies.

In a series of articles in the 1950s by Seidlin, the father of radioiodine treatment for thyroid carcinoma, and coworkers [31-33] it was well documented that there is an excess risk of leukaemia after treatment with high cumulative activities of radioiodine [34, 35], correlating with the administered total radioiodine activity [36]. In practice this means that this excess risk only materializes in patients with metastatic disease after repeated (high-activity) treatments. There are no reports in the literature of patients developing leukaemia after a single ablative activity in the adjuvant setting. An increased risk of other malignancies of organs such as the salivary glands, the breasts, the stomach or even the prostate has also been reported. It is, however, unclear how much of this risk RRA treatment is responsible for, as it has been noted in multiple studies that such carcinomas are observed in excess both before and after the diagnosis and treatment of DTC [34, 37]. The latter observation suggests that aetiological similarities and possible treatment effects are responsible for this excess in secondary malignancies [34]. Brown et al. [35] conclude that the overall risk of second primary malignancies is increased for thyroid cancer survivors and varies in relation to radioiodine therapy, latency, and age at diagnosis. In their analysis, however, the only criterion for potential radiation-related risk enhancement was if radioiodine therapy was carried out or not. Bhattacharyya and Chien even found that in multivariate analysis of DTC patients from the American Surveillance, Epidemiology and End Results Database the use of RRA was not an independent risk factor for the development of second primary malignancies [38].

Additionally, Hay et al. cite work of our group [39] in order to demonstrate that the mean radiation absorbed dose to the whole body is 0.28 Gy after the administration of $3.7 \mathrm{GBq}{ }^{131} \mathrm{I}$ for RRA. We would like to point out that there are, presently, no data correlating the whole-body absorbed dose to radiation-induced cancer risk. However, bloodbased dosimetry is important to avoid unwanted bone marrow toxicity when treating patients. What remains disputable is the amount of activity which should be administered for RRA. Randomized trials that are currently underway in the UK and France might give an answer to this question. Some approaches also use a patient-specific tailoring of the activity based on the absorbed dose to the blood [40, 41].

In an assessment of the data presented above the situation in most parts of the world will be such that the benefits of RRA outweigh the risks. In accordance with the recent EANM guidelines [5], radioiodine ablation is therefore to be regarded as a standard treatment in all patients except those with unifocal PTC $\leq 1 \mathrm{~cm}$ in diameter who lack evidence of metastasis, thyroid capsule invasion, a history of radiation exposure or unfavourable histological typing (tall-cell, columnar cell or diffuse sclerosing subtypes).

As to whether RRA treatment is beneficial, and if so, in which patients, is a nearly irresolvable issue without a randomized, controlled trial. As Dragoiescu et al. [42] have shown and Hay et al. [1] suggest, it might be feasible to conduct a prospective multicentre trial evaluating recurrences over 5-10 years. We would gladly participate in such a trial.

\section{References}

1. Hay ID, McDougall IR, Sisson JC. Perspective: the case against radioiodine remnant ablation in patients with well-differentiated thyroid carcinoma. J Nucl Med 2008;49:1395-7.

2. Sawka AM, Goldstein DP, Thabane L, Brierley JD, Tsang RW, Rotstein $\mathrm{L}$, et al. Basis for physician recommendations for adjuvant radioiodine therapy in early-stage thyroid carcinoma: principal findings of the Canadian-American thyroid cancer survey. Endocr Pract 2008;14:175-84.

3. Cooper DS, Doherty GM, Haugen BR, Kloos RT, Lee SL, Mandel SJ, et al. Management guidelines for patients with thyroid nodules and differentiated thyroid cancer. Thyroid 2006;16(2):109-42.

4. Pacini F, Schlumberger M, Dralle H, Elisei R, Smit JW, Wiersinga W. European consensus for the management of patients with differentiated thyroid carcinoma of the follicular epithelium. Eur J Endocrinol 2006;154:787-803.

5. Luster M, Clarke SE, Dietlein M, Lassmann M, Lind P, Oyen WJ, et al. Guidelines for radioiodine therapy of differentiated thyroid cancer. Eur J Nucl Med Mol Imaging 2008;35:1941-59.

6. Dietlein M, Dressler J, Eschner W, Grünwald F, Lassmann M, Leisner B, et al. Procedure guidelines for radioiodine therapy of differentiated thyroid cancer (version 3). Nuklearmedizin 2007;46:213-9.

7. Dietlein M, Dressler J, Eschner W, Grünwald F, Lassmann M, Leisner B, et al. Procedure guideline for iodine-131 whole-body scintigraphy for differentiated thyroid cancer (version 3 ). Nuklearmedizin 2007;46:206-12.

8. Schlumberger MJ. Papillary and follicular thyroid carcinoma. N Engl J Med 1998;338:297-306.

9. Mazzaferri EL, Jhiang SM. Long-term impact of initial surgical and medical therapy on papillary and follicular thyroid cancer. Am J Med 1994;97:418-28.

10. Mazzaferri EL, Kloos RT. Clinical review 128: current approaches to primary therapy for papillary and follicular thyroid cancer. J Clin Endocrinol Metab 2001;86:1447-63.

11. Tubiana M, Schlumberger M, Rougier P, Laplanche A, Benhamou E, Gardet $\mathrm{P}$, et al. Long-term results and prognostic factors in patients with differentiated thyroid carcinoma. Cancer 1985;55:794-804.

12. Simpson WJ, Panzarella T, Carruthers JS, Gospodarowicz MK, Sutcliffe SB. Papillary and follicular thyroid cancer: impact of treatment in 1578 patients. Int $\mathrm{J}$ Radiat Oncol Biol Phys 1988; 14:1063-75.

13. Utiger RD. Follow-up of patients with thyroid carcinoma. N Engl J Med 1997;337:928-30.

14. Sherman SI, Tielens ET, Sostre S, Wharam MD Jr, Ladenson PW. Clinical utility of posttreatment radioiodine scans in the management of patients with thyroid carcinoma. J Clin Endocrinol Metab 1994;78:629-34. 
15. Tenenbaum F, Corone C, Schlumberger M, Parmentier C. Thyroglobulin measurement and postablative iodine-131 total body scan after total thyroidectomy for differentiated thyroid carcinoma in patients with no evidence of disease. Eur J Cancer 1996;32A:1262.

16. Travagli JP, Cailleux AF, Ricard M, Baudin E, Parmentier C, Schlumberger $\mathrm{M}$, et al. Combination of radioiodine (131I) and probe-guided surgery for persistent or recurrent thyroid carcinoma. J Clin Endocrinol Metab 1998;83:2675-80.

17. Jonklaas J, Sarlis NJ, Litofsky D, Ain KB, Bigos ST, Brierley JD, et al. Outcomes of patients with differentiated thyroid carcinoma following initial therapy. Thyroid 2006;16:1229-42.

18. Machens A, Holzhusen HJ, Dralle H. The prognostic value of primary tumor size in papillary and follicular thyroid carcinoma. A comparative analysis. Cancer 2005;103:2269-73.

19. Sawka AM, Brierley JD, Tsang RW, Thabane L, Rotstein L, Gafni A, et al. An updated systematic review and commentary examining the effectiveness of radioactive iodine remnant ablation in well-differentiated thyroid cancer. Endocrinol Metab Clin North Am 2008;37:457-80.

20. Shattuck TM, Westra WH, Ladenson PW, Arnold A. Independent clonal origins of distinct tumor foci in multifocal papillary thyroid carcinoma. N Engl J Med 2005;352:2406-12.

21. Pacini F, Schlumberger M, Harmer C, Berg GG, Cohen O, Duntas L, et al. Post-surgical use of radioiodine (131I) in patients with papillary and follicular thyroid cancer and the issue of remnant ablation: a consensus report. Eur J Endocrinol 2005;153:651-9.

22. Schlumberger M, Berg G, Cohen O, Duntas L, Jamar F, Jarzab B, et al. Follow-up of low-risk patients with differentiated thyroid carcinoma: a European perspective. Eur J Endocrinol 2004;150:105-12.

23. Verburg FA, de Keizer B, Lips CJ, Zelissen PM, de Klerk JM. Prognostic significance of successful ablation with radioiodine of differentiated thyroid cancer patients. Eur J Endocrinol 2005; 152:33-7.

24. Hay ID, Grant CS, Taylor WF, McConahey WM. Ipsilateral lobectomy versus bilateral lobar resection in papillary thyroid carcinoma: a retrospective analysis of surgical outcome using a novel prognostic scoring system. Surgery 1987;102:1088-95.

25. Hay ID, Grant CS, Bergstralh EJ, Thompson GB, van Heerden JA, Goellner JR. Unilateral total lobectomy: is it sufficient surgical treatment for patients with AMES low-risk papillary thyroid carcinoma. Surgery 1998;124:958-64.

26. Hay ID. Selective use of radioactive iodine in the postoperative management of patients with papillary and follicular carcinoma. $\mathrm{J}$ Surg Oncol 2006;94:692-700.

27. Hölzer S, Reiners C, Mann K, Bamberg M, Rothmund M, Dudeck J, et al. Patterns of care for patients with primary differentiated carcinoma of the thyroid gland treated in Germany during 1996. U. S. and German Thyroid Cancer Group. Cancer 2000;89:192-201.

28. Solans R, Bosch JA, Galofre P, Porta F, Roselló J, Selva-O'Callagan A, et al. Salivary and lacrimal gland dysfunction (sicca syndrome) after radioiodine therapy. J Nucl Med 2001;42:738-43.
29. Silberstein EB. Reducing the incidence of 131 I-induced sialadenitis: the role of pilocarpine. J Nucl Med 2008;49:546-9.

30. Kloos RT, Duvuuri V, Jhiang SM, Cahill KV, Foster JA, Burns JA. Nasolacrimal drainage obstruction from radioactive iodine therapy for thyroid carcinoma. J Clin Endocrinol Metab 2002;87:5817-20.

31. Seidlin SM, Siegal E, Yalow AA, Melamed S. Acute myeloid leukemia following prolonged iodine-131 therapy for metastatic thyroid carcinoma. Science 1956;123:800-1.

32. Seidlin SM, Siegel E, Melamed S, Yalow AA. Occurrence of myeloid leukemia in patients with metastatic thyroid carcinoma following prolonged massive radioiodine therapy. Bull N Y Acad Med 1955;31:410.

33. Seidlin SM, Yalow AA, Siegel E. Blood radiation dose during radioiodine therapy of metastatic thyroid carcinoma. Radiology 1954;63:797-813.

34. Ronckers CM, McCarron P, Ron E. Thyroid cancer and multiple primary tumors in the SEER cancer registries. Int $\mathrm{J}$ Cancer 2005;117:281-8.

35. Brown AP, Chen J, Hitchcock YJ, Szabo A, Shrieve DC, Tward JD. The risk of second primary malignancies up to three decades after the treatment of differentiated thyroid cancer. J Clin Endocrinol Metab 2008;93:504-15.

36. Rubino C, de Vathaire F, Dottorini ME, Hall P, Schvartz C, Couette JE, et al. Second primary malignancies in thyroid cancer patients. Br J Cancer 2003;89:1638-44.

37. Verkooijen RB, Smit JW, Romijn JA, Stokkel MP. The incidence of second primary tumors in thyroid cancer patients is increased, but not related to treatment of thyroid cancer. Eur J Endocrinol 2006;155:801-6.

38. Bhattacharyya N, Chien W. Risk of second primary malignancy after radioactive iodine treatment for differentiated thyroid carcinoma. Ann Otol Rhinol Laryngol 2006;115: $607-10$.

39. Hänscheid H, Lassmann M, Luster M, Thomas SR, Pacini F, et al. Iodine biokinetics and dosimetry in radioiodine therapy of thyroid cancer: procedures and results of a prospective international controlled study of ablation after rhTSH or hormone withdrawal. J Nucl Med 2006;47:648-54.

40. Leeper RD. The effect of 131I therapy on survival of patients with metastatic papillary or follicular thyroid carcinoma. J Clin Endocrinol Metab 1973;36:1143-52.

41. Lassmann M, Hänscheid H, Chiesa C, Hindorf C, Flux G, Luster M. EANM dosimetry committee series on standard operational procedures for pre-therapeutic dosimetry I: blood and bone marrow dosimetry in differentiated thyroid cancer therapy. Eur J Nucl Med Mol Imaging 2008;35:1405-12.

42. Dragoiescu C, Hoekstra OS, Kuik DJ, Lips P, Plaizier MA, Rodrigus PT, et al. Feasibility of a randomized trial on adjuvant radio-iodine therapy in differentiated thyroid cancer. Clin Endocrinol 2003;58:451-5. 